\title{
Bone formation in custom-made cranioplasty: evidence of early and sustained bone development in bioceramic calcium phosphate implants. Patient series
}

\author{
Jimmy Sundblom, MD, PhD, ${ }^{1}$ Fabjola Xheka, MSc, ${ }^{2,3}$ Olivera Casar-Borota, MD, $\mathrm{PhD},{ }^{2,3}$ and Mats Ryttlefors, MD, PhD ${ }^{1}$ \\ Departments of ${ }^{1}$ Neuroscience Neurosurgery and ${ }^{2}$ Clinical Pathology, Uppsala University Hospital, Uppsala, Sweden; and ${ }^{3}$ Department of Immunology, Genetics and Pathology, \\ Uppsala University, Uppsala, Sweden
}

BACKGROUND Implant failure (IF) rates in cranioplasty remain high despite efforts to reduce the incidence. New biomaterials may be part of the solution for this problem. Formation of autologous bone in implants may reduce rates of infection and subsequent failure.

OBSERVATIONS Four patients with calcium phosphate implants supported by titanium mesh and undergoing surgery for reasons unrelated to IF were included in this series. Samples from the implants were microscopically examined. Pathological studies proved the formation of autologous bone in the calcium phosphate implants.

LESSONS Bone and blood vessel formation in the implants and diminished foreign body reaction to autologous bone may reduce the rates of IF.

https://thejns.org/doi/abs/10.3171/CASE20133

KEYWORDS cranioplasty; bone formation; calcium phosphate; implant failure

Cranioplasty to repair defects in the skull and adjacent bone is one of the oldest surgical procedures for which we have archaeological evidence. ${ }^{1}$ Although the procedure has been performed for thousands of years, we still wrestle with complications, with reported rates of implant failure (IF) ranging from $10 \%$ to $30 \%^{2-4}$ when foreign materials are used. Even with cranioplasty with autologous bone, the rates of surgical site infection (SSI) are high.

Another significant clinical obstacle when foreign materials such as polymethyl methacrylate or polyetheretherketone are introduced is poor bone and soft tissue integration, possibly eliciting foreign body reactions. ${ }^{5}$

Decreasing the IF rate is thus a high priority, and one strategy to reach this goal is the use of modern biomaterials, such as glass fiber-reinforced composite materials or bioceramic calcium phosphate (CaP) implants mimicking the nonorganic bony matrix. ${ }^{6,7}$ Some promise has also been shown for the use of bone morphogenetic protein 2 , collagen, and polylactide in the repair of cranial defects. ${ }^{8}$

The properties of these materials are suggested to decrease the rate of foreign body reaction, improve cosmetic appearance concerning skin quality, and decrease revision rates. Integration of cranioplasty with adjacent bone is suggested to occur when using
CaP-based implants, and the designs have in some cases been adjusted to improve these properties further, such as by using a mosaic tile design. ${ }^{9}$ Osseointegration would create a blood supply and diminish the risk of late IF due to skin lesions or slight trauma, a concern when foreign materials are implanted anywhere in the body. Nevertheless, to increase structural stability and to create a scaffold for complex three-dimensional shapes, newer CaP implants incorporate a titanium mesh. ${ }^{6}$

Data showing bone integration of $\mathrm{CaP}$ cranioplasty implants are available from animal studies and small materials reported from companies developing implants, ${ }^{9,10}$ but these implants have not been investigated in an unbiased clinical use setting. Here, we report the cases of four patients receiving commercially available custom-made $\mathrm{CaP}$ implants, which, for reasons unrelated to IF, were surgically exposed, and we describe histological microscopic findings proving the integration of implants with existing bone.

\section{Study Description}

Four patients with preexisting $\mathrm{CaP}$ implants undergoing anatomically adjacent procedures or redo surgery for reasons unrelated to IF were recruited from the neurosurgical department at Uppsala

ABBREVIATIONS CaP = calcium phosphate; IF = implant failure; $\mathrm{SSI}=$ surgical site infection; $\mathrm{TBI}=$ traumatic brain injury. INCLUDE WHEN CITING Published online April 26, 2021; DOI: 10.3171/CASE20133.

SUBMITTED November 29, 2020. ACCEPTED December 11, 2020.

(c) 2021 The authors, CC BY-NC-ND 4.0 (http://creativecommons.org/licenses/by-nc-nd/4.0/). 
University Hospital. Ages are reported according to the time of the original cranioplasty procedure.

\section{Case 1}

Case 1 has been reported previously. ${ }^{11}$ The patient was a 39 -year-old female with a giant intraosseous chordoid meningioma undergoing removal and repair of a large defect with a twopiece custom-made $\mathrm{CaP}$ implant. Thirteen months later, she underwent surgery of a smaller meningioma component on the contralateral side. The frontal cranioplasty was exposed, since the same incision was used. The cranioplasty was adherent to surrounding connective tissue, but the demarcation was readily seen. Several biopsies of the cranioplasty were obtained from the edges of the implant, but also from more central parts, by using rongeurs.

\section{Case 2}

Case 2 was a 24-year-old male patient with a traumatic brain injury (TBI). Because of elevated intracranial pressure refractory to medical treatment and extensive general edema, a bifrontal craniectomy was performed. Initially, a cranioplasty with autologous bone was performed, but because of resorption of bone bilaterally, revision with two separate CaP implants was performed. The implants were soaked in gentamicin to possibly decrease the risk of SSI. ${ }^{12}$ One month after revision, the patient presented with an SSI beneath the right-sided implant, leaving the left-sided implant intact. The right-sided implant was removed. After 5 months, a revision $\mathrm{CaP}$ implant was placed on the right side. The cranioplasty was not completely adherent to surrounding bone. Biopsies from the edges of the implant were obtained using rongeurs (Fig. 1).

\section{Case 3}

Case 3 was a 21-year-old male who initially underwent surgery for a low-grade glioma. Because of a postoperative epidural empyema, his bone flap was removed, and subsequently he received a $\mathrm{CaP}$ custom-made cranioplasty. Twenty-eight months after implantation, he underwent surgery for a recurrent tumor extending laterally beyond the original cranioplasty, necessitating removal of the whole cranioplasty and placement of a new custom-made implant. The whole implant was removed along with a rim of autologous bone. It was fully adherent to the bone but easily dissected from the underlying dural layer. The whole implant was investigated for this study.

\section{Case 4}

Case 4 was a 40-year-old female who underwent cranioplasty following removal of a bone flap because of an epidural empyema after surgery for a large left frontal meningioma. A custom-made $\mathrm{CaP}$ implant was inserted. Thirty-four months later, she underwent surgery for a de novo meningioma in proximity to the previous surgical field. A biopsy from the rim of the original cranioplasty was obtained and investigated.

\section{All Cases}

All implants were designed and manufactured by OssDesign. The CaP compound used comprised monetite, $\beta$-calcium pyrophosphate, $\beta$-tricalcium phosphate, and brushite.

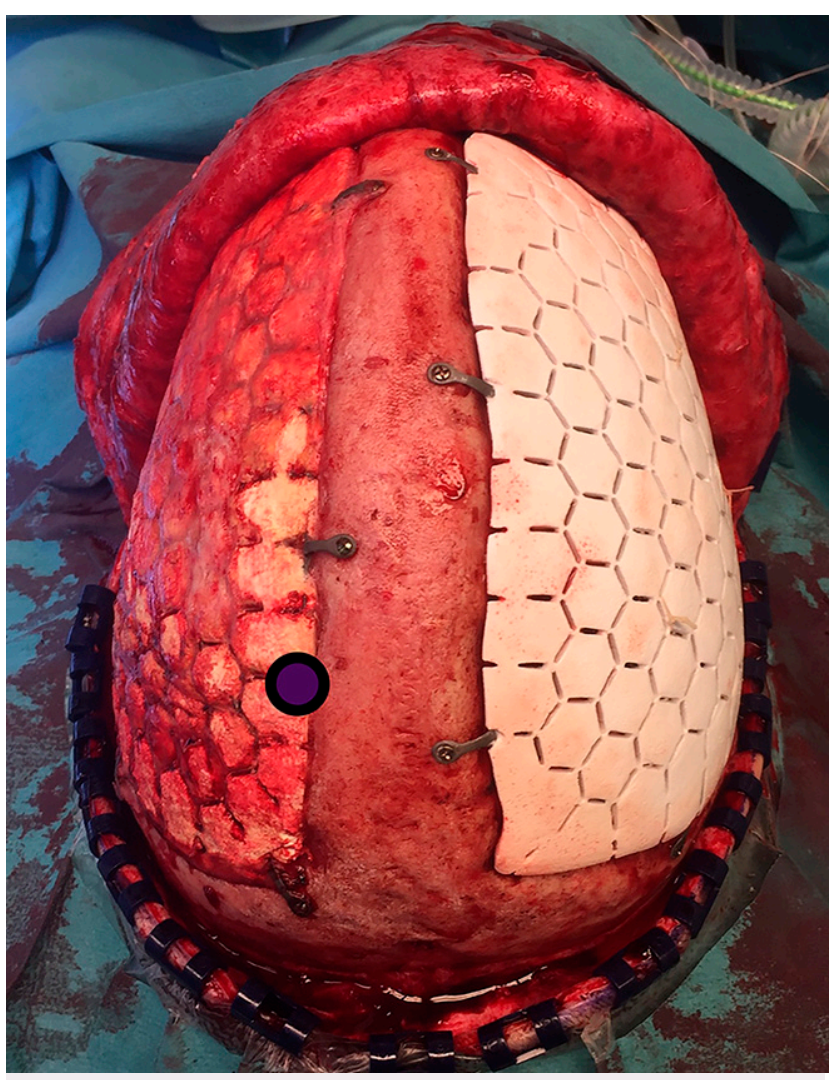

FIG. 1. Intraoperative photograph of existing left-sided implant from case 2. Circled area represents site of biopsy taken 6 months after implantation. Newly placed implant is shown on the right side for comparison.

All patients provided written informed consent, except for the patient in case 2, for whom consent was provided by his next of kin due to cognitive impairment after his TBI. The study was approved by the regional ethics board (2019-01321) in Uppsala, Sweden. The patients' characteristics are described in Table 1.

All biopsies, including the implant fully removed, were fixed in $4 \%$ buffered formalin and underwent decalcination. Multiple crosssections were taken from peripheral and central parts of the specimens and embedded in paraffin. Four-micrometer-thick slides were cut and stained using standard hematoxylin and eosin stain and were subsequently analyzed using optic microscopy.

All investigated biopsies showed ingrowth/formation of vascularized autologous bone within the bioceramic implant. Bone histology was preserved with the rich presence of osteocytes, osteoblasts, and normally developed blood vessels. The bone trabeculae were surrounded by residual foreign material, with osteoclasts engulfing the foreign material easily identifiable. In the sections from the peripheral part of the implants, bone marrow was well represented in the preexisting bone, being sparser in the transition area and not identifiable in the newly formed bone (Fig. 2). In cases 1 and 3 , more central areas of the implants were investigated, at most 25 $\mathrm{mm}$ from the edges of the implant, and bone formation was also evident there. 
TABLE 1. Patient characteristics

\begin{tabular}{|c|c|c|c|c|c|c|c|}
\hline $\begin{array}{l}\text { Case } \\
\text { No. }\end{array}$ & $\begin{array}{c}\text { Age at Initial } \\
\text { Cranioplasty (yrs) }\end{array}$ & $\begin{array}{l}\text { Indication for } \\
\text { Primary Procedure }\end{array}$ & $\begin{array}{l}\text { Indication for } \mathrm{CaP} \\
\text { Implant }\end{array}$ & $\begin{array}{l}\text { Indication for } \\
\text { Surgery at Biopsy }\end{array}$ & $\begin{array}{c}\text { Size of } \\
\text { Implant }\left(\mathrm{cm}^{2}\right)\end{array}$ & $\begin{array}{c}\text { Mos From } \\
\text { Primary Implant }\end{array}$ & $\begin{array}{c}\text { Material } \\
\text { Investigated }\end{array}$ \\
\hline 1 & 40 & Tumor & Tumor removal & $\begin{array}{l}\text { Adjacent tumor } \\
\text { removal }\end{array}$ & 142 & 13 & Partial biopsy \\
\hline 2 & 24 & Trauma & $\begin{array}{l}\text { Resorption of autologous } \\
\text { cranioplasty }\end{array}$ & $\begin{array}{c}\text { Revision of } \\
\text { adjacent implant }\end{array}$ & 136 & 5 & Partial biopsy \\
\hline 3 & 21 & Tumor & $\begin{array}{c}\text { Bone flap removed due } \\
\text { to SSI }\end{array}$ & Tumor recurrence & 30 & 26 & Whole implant \\
\hline 4 & 30 & Tumor & $\begin{array}{c}\text { Bone flap removed due } \\
\text { to SSI }\end{array}$ & $\begin{array}{l}\text { Adjacent tumor } \\
\text { removal }\end{array}$ & 78 & 38 & Partial biopsy \\
\hline
\end{tabular}

All investigated implants, excluding the one completely removed (case 3 ), remain in place without signs of IF after 36 (case 1), 33 (case 2), and 50 (case 3) months.

\section{Discussion}

\section{Observations}

To achieve formation of bone in any setting, such as fractures or after surgical removal of bone, three elements must be in place: osteoconduction, osteoinduction, and osteogenic cells. ${ }^{13}$ To sustain the process, angiogenesis must also take place. ${ }^{14}$ These processes have been known and applied in clinical practice in orthopedics, dentistry, and craniofacial surgery for over a century, using autologous bone and/or different materials supporting bone formation due to the use of these processes.

Repair of large defects in the cranial calvaria is challenging; autografts are not readily available without significant morbidity, and the large size of the defects presents additional problems. Cranioplasty using foreign materials such as metals or different plastic materials has thus been performed for centuries. ${ }^{15}$

The disadvantages of using foreign materials are well known, including foreign body reaction ${ }^{16}$ and risk of infection.

The use of cranioplasty has been suggested to increase because of large studies showing unequivocal benefits of craniectomy
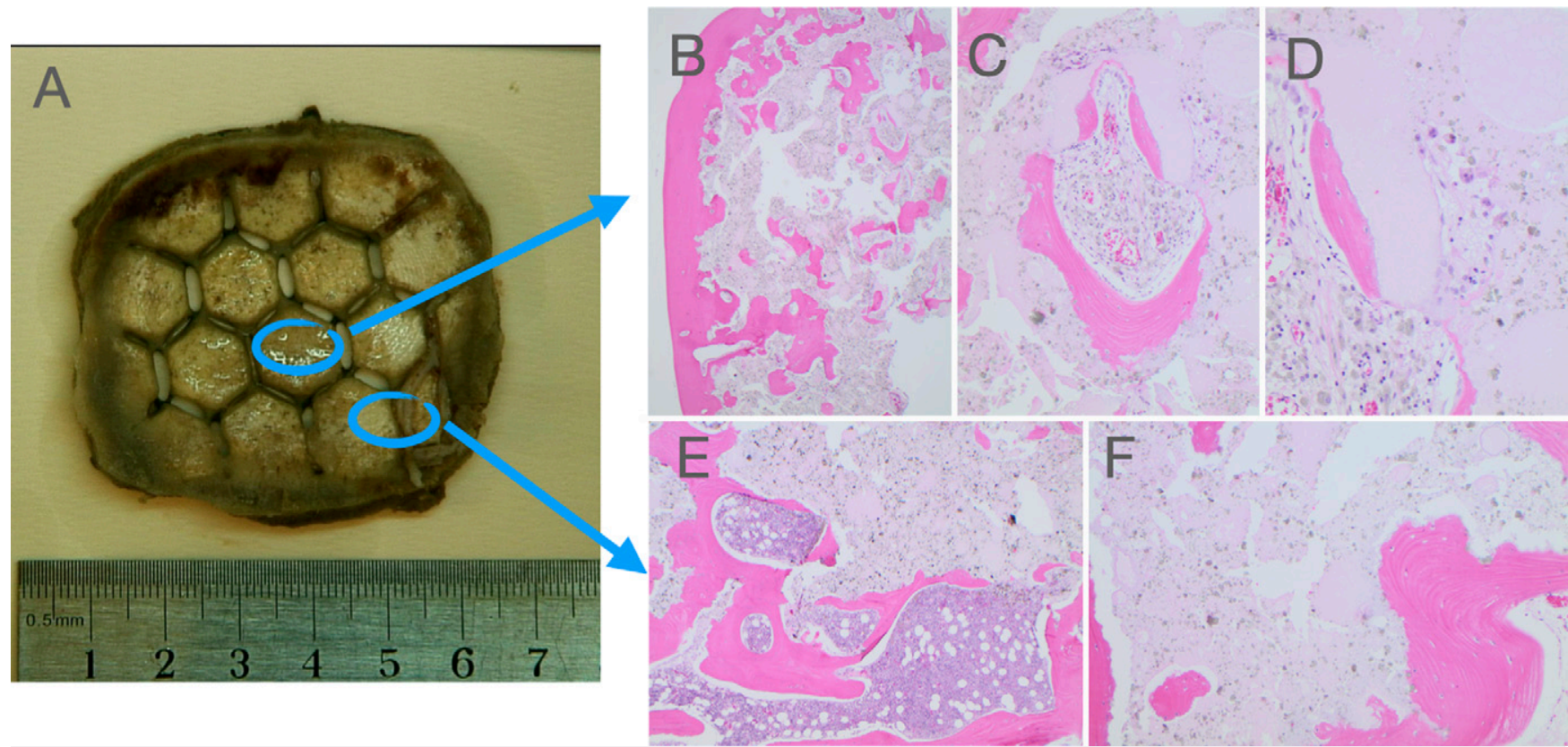

FIG. 2. The bioceramic implant from case 3 (A). In the histological slides (hematoxylin and eosin stain) from the central part of the implant, a new bone formation is present, surrounded by residual foreign material $(\mathbf{B}$; original magnification $\times 20)$ with normal-appearing osteocytes, osteoblasts, and blood vessels $(\mathbf{C}$; original magnification $\times 100)$ and osteoclasts engulfing the residual foreign material (D; original magnification $\times 200)$. In the section from a peripheral part of the implant, bone marrow with normal hematopoiesis is present in the preexisting bone $(\mathbf{E}$; original magnification $\times 40)$ and not in the areas of new bone formation $(\mathbf{F}$; original magnification $\times 10)$. 
in conditions with intracranial swelling without clear mass lesions, such as malignant middle cerebral artery infarction and TBI. ${ }^{17-19}$ Since the rate of IF in late cranioplasty, including with preserved autologous bone, is high, new and better biomaterials are welcome additions to the surgical options available. Of the recently developed biomaterials, CaP shows promise as a way to reduce IF rates, partly because of data suggesting the formation of autologous bone replacing the CaP implant over time. ${ }^{10,20}$ The osteoconductivity of CaP ceramics experimentally outdoes, for instance, that of deproteinized bone ${ }^{21}$ (suggesting superiority over frozen autologous bone flap, which is commonly used in cranioplasty after trauma or cerebral infarction). The osteoinductive properties of the material are also important and compare favorably with, for instance, hydroxyapatite, which is osteoconductive but not osteoinductive. ${ }^{22}$

The process through which osteointegration takes place in $\mathrm{CaP}$ implants is not fully known. An interesting finding, confirmed in this study, is the fact that bone integration occurs as effectively in the central parts of the implants as in the bone-adjacent parts. This may be attributable to the release of $\mathrm{Ca}$ and $\mathrm{P}$ ions, growth factors, and cytokines eliciting inflammatory and regenerative responses from surrounding nonbony tissue. ${ }^{23}$

To further decrease the rate of SSI, some advocate using locally administered antibiotics when performing cranioplasty. CaP implants have been shown in vitro to exhibit the sustained release of gentamicin. $^{12}$ Gentamicin negatively affects cell proliferation, ${ }^{24}$ which could potentially inhibit bone formation. In case 2 in this study, gentamicin soaking was performed at implantation, and osteointegration was nevertheless seen, suggesting that gentamicin soaking does not inhibit the osteoconductive process.

The advantages of osteointegration in cranioplasty are readily imagined. In neurosurgical practice, it is not uncommon to see late $\mathrm{IF}$, which may be caused by a slight trauma upon exposing the cranioplasty and allowing an entry port for bacteria. If, in such a case, integration with vascularized bone has occurred, it may be possible to treat an infection with only systemic antibiotics without removal of the implant. Currently, in such a scenario, a foreign implant would be removed, followed by long-term antibiotic treatment before a revision cranioplasty. There are reports of successful treatment with only systemic antibiotics in such cases. ${ }^{12}$

Advantages are also readily imagined in cases in which the cranioplasty is surgically exposed for other reasons, a very risky proposition given the risk of contamination. If osteointegration has occurred, the risk for the implant should not be higher than for osteitis in surrounding autologous bone (i.e., very small). Also, the long-term structural strength of the implant may be improved and sustained by the osseointegration.

\section{Lessons}

Early and sustained osteointegration of $\mathrm{CaP}$ implants in cranioplasty occur and should confer benefits for patients in need of the procedure. Further research, including a randomized controlled trial comparing different biomaterials and autologous bone, should be conducted.

\section{References}

1. Shah AM, Jung $H$, Skirboll S. Materials used in cranioplasty: a history and analysis. Neurosurg Focus. 2014;36(4):E19.
2. Punchak M, Chung LK, Lagman $C$, et al. Outcomes following polyetheretherketone (PEEK) cranioplasty: systematic review and meta-analysis. J Clin Neurosci. 2017;41:30-35.

3. Honeybul S, Ho KM. Cranioplasty: morbidity and failure. $\mathrm{Br} \mathrm{J}$ Neurosurg. 2016;30(5):523-528.

4. Thien A, King NK, Ang BT, et al. Comparison of polyetheretherketone and titanium cranioplasty after decompressive craniectomy. World Neurosurg. 2015;83(2):176-180.

5. Neovius E, Engstrand T. Craniofacial reconstruction with bone and biomaterials: review over the last 11 years. J Plast Reconstr Aesthet Surg. 2010;63(10):1615-1623.

6. Engstrand T, Kihlström L, Neovius E, et al. Development of a bioactive implant for repair and potential healing of cranial defects. J Neurosurg. 2014;120(1):273-277.

7. Posti JP, Piitulainen JM, Hupa L, et al. A glass fiber-reinforced composite-bioactive glass cranioplasty implant: a case study of an early development stage implant removed due to a late infection. J Mech Behav Biomed Mater. 2015;55:191-200.

8. Kohan E, Roostaeian J, Yuan JT, et al. Customized bilaminar resorbable mesh with BMP-2 promotes cranial bone defect healing. Ann Plast Surg. 2015;74(5):603-608.

9. Engstrand T, Kihlström L, Lundgren K, et al. Bioceramic implant induces bone healing of cranial defects. Plast Reconstr Surg Glob Open. 2015;3(8):e491.

10. Omar O, Engstrand T, Kihlström Burenstam Linder L, et al. In situ bone regeneration of large cranial defects using synthetic ceramic implants with a tailored composition and design. Proc Natl Acad Sci U S A. 2020;117(43):26660-26671.

11. Sundblom J, Nowinski D, Casar-Borota O, Ryttlefors M. Removal of giant intraosseous meningioma followed by cranioplasty using a custom-made bioceramic implant: case report. J Neurosurg. 2018; 131(3):735-739.

12. Sundblom J, Gallinetti S, Birgersson U, et al. Gentamicin loading of calcium phosphate implants: implications for cranioplasty. Acta Neurochir (Wien). 2019;161(6):1255-1259.

13. Khan WS, Rayan F, Dhinsa BS, Marsh D. An osteoconductive, osteoinductive, and osteogenic tissue-engineered product for trauma and orthopaedic surgery: how far are we? Stem Cells Int. 2012;2012:236231.

14. Kanczler JM, Oreffo RO. Osteogenesis and angiogenesis: the potential for engineering bone. Eur Cell Mater. 2008;15:100-114.

15. Harris DA, Fong AJ, Buchanan EP, et al. History of synthetic materials in alloplastic cranioplasty. Neurosurg Focus. 2014;36(4):E20.

16. Brett-Major DM, Baraniak SM, Gilhooly JE, et al. Foreign-body reaction mimicking postneurosurgical infection after cranioplasty. Mil Med. 2008;173(7):697-699.

17. Hofmeijer J, Kappelle LJ, Algra A, et al. Surgical decompression for space-occupying cerebral infarction (the Hemicraniectomy After Middle Cerebral Artery infarction with Life-threatening Edema Trial [HAMLET]): a multicentre, open, randomised trial. Lancet Neurol. 2009;8(4):326-333.

18. Jüttler E, Bösel J, Amiri H, et al. DESTINY II: DEcompressive Surgery for the Treatment of malignant INfarction of the middle cerebral arterY II. Int J Stroke. 2011;6(1):79-86.

19. Hutchinson PJ, Kolias AG, Timofeev IS, et al. Trial of decompressive craniectomy for traumatic intracranial hypertension. N Engl J Med. 2016;375(12):1119-1130.

20. Eliaz N, Metoki N. Calcium phosphate bioceramics: a review of their history, structure, properties, coating technologies and biomedical applications. Materials (Basel). 2017;10(4):E334

21. Uetanabaro LC, Claudino M, Zancan R, et al. Osteoconductivity of biphasic calcium phosphate ceramic improves new bone formation: a histologic, histomorphometric, gene expression, and microcomputed tomography study. Int J Oral Maxillofac Implants. 2020;35(1):70-78. 
22. Jeong J, Kim JH, Shim JH, et al. Bioactive calcium phosphate materials and applications in bone regeneration. Biomater Res. 2019;23:4.

23. Tang Z, Li X, Tan Y, et al. The material and biological characteristics of osteoinductive calcium phosphate ceramics. Regen Biomater. 2018;5(1):43-59.

24. Isefuku S, Joyner CJ, Simpson AH. Gentamicin may have an adverse effect on osteogenesis. J Orthop Trauma. 2003;17(3): 212-216.

\section{Disclosures}

The authors report no conflict of interest concerning the materials or methods used in this study or the findings specified in this paper.

\section{Author Contributions}

Conception and design: Sundblom, Casar-Borota, Ryttlefors. Acquisition of data: all authors. Analysis and interpretation of data: all authors.

Drafting the article: Sundblom, Xheka, Ryttlefors. Critically revising the article: Casar-Borota, Ryttlefors. Reviewed submitted version of manuscript: Sundblom, Casar-Borota, Ryttlefors. Approved the final version of the manuscript on behalf of all authors: Sundblom. Administrative/technical/material support: Casar-Borota. Study supervision: Ryttlefors.

\section{Correspondence}

Jimmy Sundblom: Uppsala University Hospital, Uppsala, Sweden. jimmy.sundblom@neuro.uu.se. 